\title{
The crypto currency as money of digital economy
}

\author{
Egor V. Dudukalov ${ }^{1}$, Yulia A. Geroeva ${ }^{1}$, Mariya A. Shtepa ${ }^{1}$, and Denis Ushakov, ${ }^{2, *}$ \\ ${ }^{1}$ Russian Presidential Academy of National Economy and Public Administration, South-Russian \\ Institute of Management, Rostov-on-Don, Russia \\ ${ }^{2}$ Suan Sunandha Rajabhat University, Bangkok, Thailand
}

\begin{abstract}
The digitalization of monetary and foreign exchange circulation is one of the leading institutional and infrastructural transformations at the beginning of the 21 st century, affecting not only the long-term interests and priorities of business development and state progress, but also the very principles of public-private relations within the socio-economic system. The article assess opinions of 350 experts from 8 sectors of the economy of Russia and Thailand for the prospects of cryptocurrency (on the example of Bitcoin) introducing into official calculations, turnover, accumulation, as well as the readiness of business and state for this digital transformation in context of the Digital Economy trend globalization. The research implemented the quantitative methodology throughout using a survey and the data had been treated using SPSS statistical tool for hypotheses validation. The empirical data obtained confirmed the priorities of the factors for accelerating the currencies cryptotization, identified the main problems of Russian and Thai business, pessimizing the potential for using Bitcoins, and the concept of state financial regulation modernizing in the dynamics of digitalization.
\end{abstract}

\section{Introduction}

The public interest in cryptocurrencies observed these days is associated with intrigue on their future. Such high attention is due to the willing to understand what affects their popularity and how they can be embedded in the economy.

Initially, in 2009, Bitcoin was worth a few cents and only by February 2011, its value rose to $\$ 1$. With the advent of cryptocurrency exchanges, the disclosure of the potential and opportunities of using cryptocurrencies, their value began to grow [1].

Bitcoin has no intrinsic liquidation value: it does not give rights to future cash flows, is not a debt obligation, and there is no guarantee of its use as payment for goods and services.

The price of Bitcoin is completely determined by the public's desire to buy it and the desire of the owners (early miners and investors) to take profits. The value of a cryptocurrency consists of its ability to perform a transactional (payment) function and a function of income generating (for investors).

\footnotetext{
*Corresponding author: denis.us@ssru.ac.th
} 
This specificity of Bitcoin has formed an extremely high volatility of its rates, its exposure to fluctuations depending on information and market conditions, has led to a powerful redistribution of real assets between companies and countries over the past 5-8 years.

On the one hand, Bitcoin is increasingly being officially viewed as an alternative to traditional money (in 2018, for example, the first delivery of gasoline from China to Singapore, was entirely built on blockchain technology; the Fed said that it does not consider cryptocurrencies as a threat to the US financial system; in China the fund for investment in crypto worth $\$ 1.6$ billion was presented) [2].

On the other hand, the volatility of Bitcoin, the low security of cyber business, the reluctance of the state to limit its own regulatory capabilities and competencies in the traditionally sensitive financial sphere pessimize the prospects of crypto-finance. It requires governments and businesses to reach a new consensus where Government limits itself in favor of the blockchain while creating a protected and secure space of action, and business provides openness and transparency necessary for effective blockchain and cryptocurrency deep implementation.

The readiness for such a consensus on the part of Thai and Russian businesses has become a problematic field of the proposed study.

Research objectives

- to determine the significance of the technological and economic factor of currency circulation cryptotization the modern conditions of the business community development in Russia and Thailand;

- to analyze the attitude of Russian and Thai business representatives to the possible cryptization of currency circulation, to identify trends and patterns of pessimization or optimization of these prospects.

\section{Literature review}

\subsection{Factors Influencing Cryptocurrencies Prices}

Since 2009, particularly cryptocurrencies and Bitcoin have been modelled. But the popularity of these new currencies has been growing like never before in the last years, and especially in 2017. Moreover, these "assets," since people invest in them and spend money on them, have just raised their costs. Millions of dollars have been invested on emerging coins in this period as it showed by [3] and there is intrinsic value in crypto currencies.

[4] points out three distinct forms of market generators, grouped into two categories: internal and external influences (supply and demand) (crypto-market, macro-financial and political). The internal considerations are supply and demand-related, such as transaction prices, the incentive scheme for each crypto-currency, the mining challenge of, the minimal or infinite quantity of circulating coins and the fork. Bitcoin has tracked their BTC supply in compliance with block height and block incentives [5].

The crypto-market comprises the attraction, popularity, market trend and speculation created by investors and the media. Macro-financial considerations including capital prices, exchange rate, gold price, and interest rates at a certain point of time.

There are considerations that may impact Bitcoin's or cryptocurrency rates, in addition to demand variables. [6] carried out the first Bitcoin price creation report, with the conventional determinants of currency values, such as consumer strengths in supply and demand, in mind as well as considerations unique to digital currencies, such as attractiveness of investment. 
As previously stated in [7], the relationship of supply and demand from Bitcoin is a big driver of Bitcoin price. The results dictate the number of coins circulating and, therefore, the price shortage. Demand is generally measured in conjunction with the quantity of transactions as Bitcoin is used as a platform for trading various forms of services and products. "No standard economic theories, such as cash flows model, acquisitive power parity, and uncovered interest-rate parity, can explain Bitcoin's price formation, since there are no features on the Bitcoin markets for the monetary supply and demand that are usually the basis for monetary pricing" according to [5].

\subsection{Economic Drivers}

"The values of a currency are standardly moved by its use, production, and market levels in economic theory. [8] Bitcoin has been studies that indicate that in the long term it appreciates the use that it is rendered mainly of trade, non-exchange and the higher price in the short term improves the purchases of exchanges [9]. This implies that Bitcoin complies with the planned economic theory, in particular the theory of money quantity. Market prices are often a big driver of Bitcoin price, since service and commodities are supposed to be accessible anywhere for the same price, whereas the differences are regulated by exchange rates [6].

This ensures the first currency should be appreciated and a rise in the exchange rate should be checked if price of one currency falls compared to price level of another currency. [10] proved that this partnership is unfavourable and agreed that Bitcoin's behaviour should not, in the long term, refute the rule of one price. The production of capital functions such that its rise contributes to cheaper costs and to a negative ratio. However, only long horizons are required to play a function because of the algorithm presented by Bitcoin and its Block-chain technologies [5].

\subsection{Technical Drivers}

The mining operation and the mines themselves are the technological drivers. Miners require a lot of computing resources to overcome the challenges they encounter to sustain the creation of new Bitcoins to bring them into circulation. "The computational efficiency of the mine is then minimized and reflects the current computational power of the hash system" [11]. Mining operations are, thus, an investment opportunity as computing resources, either in the form of coins or in part, is traded for incentives.

The price of Bitcoin and mining operation and hash rate are separate consequences. Considering mining as an investment implies consumers spend in hardware to solve problems and collect benefits. Mining implicitly allows miners to acquire coins. This may have two theoretical consequences. The price rise will enable participants to invest in hardware and start mining, resulting in a greater hash rate and greater difficulty in earning coins. The higher the hash rate and the harder to get the revenue, as well as the hardware and energy bills, could, however, lead more miners to quit their mining pools [2].

\subsection{The Impact of Volatility on Cryptocurrencies}

A significant amount of the most recent research, such as, for example, [12-14], is devoted to the problem of forecasting the crypto currency exchange rate, as well as assessing its impact on stock quotes and economic indicators. This, in our opinion, indicates a movement towards the possibility of large-scale use of the crypto currency as money of digital economy in the medium term. 
Volatility was previously listed as one of the greatest challenges today confronted by cryptocurrencies. Bitcoin's exchange-rate instability, which reflects far greater volatility than other currencies, has been about 133 per cent since 2013. Since early 2013, the volatility of gold perceived as a "risk-free" investment has been 22 percent. In contrast, we can see that the most commonly exchanged commodity since 2013 has volatility of about $20 \%$ to $30 \%$, whereas even riskier stocks are barely more than $100 \%$. Bitcoin has been one of the most unpredictable commodities since 2011 with regular price swings of more than 50 percent [15].

In comparison, in the absence of a financial crisis bonds and securities typically do not fluctuate more than $50 \%$. Today, Bitcoin also shows major price swings, but the size of them has declined and uncertainty has diminished judging from [15]. The volatility in Bitcoin was $20 \%$ in January 2017 compared with the previous five years and $28 \%$ lower in January 2016. Many buyers discovered in April 2016 that Bitcoin has remained steady for a brief amount of time than the gold level, a smaller level of uncertainty. This was achieved because of different factors: more stability and liquid spot trading, greater regulatory transparency, more broad ownership, and more accurate market finding knowledge. The volatility of Bitcoin has declined dramatically over the years, but remains the most unpredictable of the large asset class [5].

\section{Methodology Implemented}

To conduct the study, a survey of 350 experts regarding the prospects for introducing Bitcoin as a settlement currency in terms of existing economic and technological trends was completed. The details of the interviewed experts is shown in Table 1.

Data received from the experts was analyzed using Regression Analysis, Pearson Correlations and Factor Analysis, which made it possible to test the hypotheses of the study regarding the prospects for introducing Bitcoin into official monetary calculations in the future.

For data collection and then data analysis, a questionnaire for a certain number of participants should be distributed using the SPSS statistical methodology for analytical proof of the research hypotheses.

Table 1. Demographic and professional characteristics of the interviewed experts (compiled by the authors).

\begin{tabular}{|c|c|c|c|c|}
\hline & & & $\begin{array}{c}\text { Russia } \\
\text { presenters }\end{array}$ & $\begin{array}{l}\text { Thailand } \\
\text { presenters }\end{array}$ \\
\hline \multirow{2}{*}{1} & \multirow{2}{*}{ Gender } & Male & 112 & 114 \\
\hline & & Female & 88 & 36 \\
\hline \multirow{3}{*}{2} & \multirow{3}{*}{ Education level } & Bachelor & 46 & 36 \\
\hline & & Magister (Master) & 117 & 108 \\
\hline & & Doctoral, post-doc & 37 & 6 \\
\hline \multirow{3}{*}{3} & \multirow{3}{*}{ Experience } & $5-10$ years & 95 & 67 \\
\hline & & $10-20$ years & 74 & 48 \\
\hline & & $>20$ years & 31 & 35 \\
\hline \multirow{3}{*}{4} & \multirow{3}{*}{ Job position } & consulting & 62 & 79 \\
\hline & & mid manager & 78 & 54 \\
\hline & & top manager & 60 & 17 \\
\hline \multirow{4}{*}{5} & \multirow{4}{*}{$\begin{array}{l}\text { Relations to } \\
\text { business }\end{array}$} & consulter & 60 & 25 \\
\hline & & employee & 54 & 67 \\
\hline & & co-owner & 75 & 52 \\
\hline & & major owner & 11 & 4 \\
\hline 6 & Area of business & finance, banking, insurance & 14 & 19 \\
\hline
\end{tabular}




\begin{tabular}{|l|l|c|c|}
\hline \multirow{4}{*}{} & transport, logistic & 22 & 26 \\
\cline { 2 - 4 } & industry & 31 & 16 \\
\cline { 2 - 4 } & agriculture & 29 & 27 \\
\cline { 2 - 4 } & sales & 19 & 14 \\
\cline { 2 - 4 } & service, tourism & 26 & 12 \\
\cline { 2 - 4 } & construction & 21 & 26 \\
\cline { 2 - 4 } & high tech & 38 & 10 \\
\hline \multicolumn{2}{|r|}{ Totally surveyed } & $\mathbf{2 0 0}$ & $\mathbf{1 5 0}$ \\
\hline
\end{tabular}

\subsection{Regression Analysis}

Table 2. Results of Regression Analyze (compiled by the authors).

\begin{tabular}{|c|c|c|c|c|}
\hline \multicolumn{5}{|c|}{ Model Summary } \\
\hline Model & R & R Square & Adjusted R Square & Std. Error of the Estimate \\
\hline 1 & $.623^{\mathrm{a}}$ & .388 & .373 & .554 \\
\hline
\end{tabular}

a. Predictors: (Constant): Economic Drivers, Technical Drivers

\begin{tabular}{|c|c|c|c|c|c|c|}
\hline \multicolumn{7}{|c|}{ Coefficients } \\
\hline & \multirow[t]{2}{*}{ Model } & \multicolumn{2}{|c|}{$\begin{array}{l}\text { Unstandardized } \\
\text { Coefficients }\end{array}$} & \multirow{2}{*}{$\begin{array}{c}\begin{array}{c}\text { Standardized } \\
\text { Coefficients }\end{array} \\
\text { Beta } \\
\end{array}$} & \multirow[t]{2}{*}{$\mathbf{t}$} & \multirow[t]{2}{*}{ Sig. } \\
\hline & & B & Std. Error & & & \\
\hline \multirow{3}{*}{1} & (Constant) & .560 & .224 & .112 & 2.496 & .014 \\
\hline & Economic & .128 & .060 & .150 & 2.128 & .035 \\
\hline & Technical & .395 & .062 & .464 & 6.324 & .002 \\
\hline
\end{tabular}

a. Dependent Variable: Acceptance of Bitcoin

Regression is an inferential statistical test that analyzes the data gathered and validates the findings of the study on the basis of a 5 percent margin of error. However, over 150 participants were distributed, 132 participants addressed the survey and the findings will be disclosed as follows:

- There is a significant relationship among economic drivers and acceptance of Bitcoin since the margin error is 0.035 which is lower than 0.05 ;

- There is a significant relationship among and technical drivers and acceptance of Bitcoin since the margin error is 0.02 which is lower than 0.05 .

Thus, based on the above analysis the hypotheses can be validated as follows:

H1: There is no significant relationship among economic driver and acceptance of Bitcoins - Rejected.

H2: There is no significant relationship among technical driver and acceptance of Bitcoins - Rejected.

Thus the following equation can be explained as follows:

$$
Y=A+B X 1+B X 2
$$

Where $\mathrm{Y}=$ dependent variable, $\mathrm{A}=$ constant, $\mathrm{B}=$ coefficient, $\mathrm{X}=$ independent variables.

This can lead us for the following:

$$
\text { Acceptance of Bitcoin }=0.035 \text { Economic }+0.002 \text { Technical }
$$

Thus, the findings can be proposed as follows:

- The acceptance of Bitcoin decreases by 0.035 for every one unit increase in economic driver;

- The acceptance of Bitcoin is affected by 0.002 for every one unit increase in technical driver. 
The researchers then proved that the other hypotheses of analysis are correct and that the null hypotheses are denied and also researched the relation between the variables if the relation is proportional or inverse.

\subsection{Pearson Correlations}

Table 3. Results of Pearson Correlation (compiled by the authors).

\begin{tabular}{|c|c|c|}
\hline \multirow{2}{*}{ Economic Driver } & Pearson Correlation & Acceptance of Bitcoins \\
\cline { 2 - 3 } & Sig. (2-tailed) & -.043 \\
\cline { 2 - 3 } & $\mathrm{N}$ & .623 \\
\hline \multirow{3}{*}{ Technical Driver } & Pearson Correlation & 350 \\
\cline { 2 - 3 } & Sig. (2-tailed) & .331 \\
\cline { 2 - 3 } & $\mathrm{N}$ & .000 \\
\hline
\end{tabular}

The Pearson method is another measure to check the favorable or negative association depending on a predictor defined as the Pearson coefficient. The findings are, however, the following:

This is a negative link between economic driver and Bitcoin adoption, as the negative connection was seen by the Pearson Correlation. Thus the greater the economic driver the lower the adoption of Bitcoin becomes so the further established is it the reverse association.

There is a strong link regarding technical driver and adoption of Bitcoins. The magnitude of the equation was 0.331 .

The Pearson correlation test is structured to determine whether the correlation is positive or negative depending on a statistic defined as the individual coefficient. The regression test just indicates whether the coefficient is connected or not. There are also similar and complementary measures for associations with Pearson and regressive research. In the next part, the factor analysis process, a method that analyzes whether or not the data obtained for the variable is credible based on 0.7. This examination helps the researchers to figure out which problems and variables emerge from some outliers.

\subsection{Factor Analysis}

Table 4. Results of Factor Analyze (compiled by the authors).

\begin{tabular}{|c|c|}
\hline & Reliability \\
\hline Economic & .888 \\
\hline Technical & .868 \\
\hline Acceptance & .822 \\
\hline
\end{tabular}

The study of the component is aimed at determining the quality of the answers in each equation. The collected data associated with this variable are valid if the coefficient has been greater than 0.7 .

The results of the validity of the variables are as follows: Reference to the above analyzes found from the statistical tool SPSS:

- For economic drivers-related questions there is a valid relationship, as the trustworthiness coefficient shows a level of 0.888 ;

- The correlation between technical-related issues is valid because the reliability coefficient is 0.868 which is above 0.7 ; 
- For questions of acceptance, there is a valid correlation, given that the reliability coefficient is 0.822 which is above 0.7 .

\section{Main Findings}

Taking into account the results of the expert opinion analysis the following results were obtained:

1. In general, the Russian business community is more optimistic about the prospects for Bitcoin introducing into circulation in comparison with the Thai one (the values of the coefficients are 64.2 and 39.8, respectively), which is generally justified by the higher level of innovative and digital infrastructure development in Russia [16, 17], more restrictive financial regulation (including digital) and more widespread digital fraud in Thailand.

2. Most of the interviewed experts consider Bitcoin more as a tool for secure payments (66\% - in Russia, 78\% - in Thailand), while trust in Bitcoin as a means of accumulating savings is practically zero and is not perceived as a serious prospect. This is justified by the high instability of the Bitcoin exchange rate, the weak predictability of its fluctuations [18], the secrecy of information about mining, the weakness of the existing system of legal regulation of Bitcoin turnover.

3. It should be noted that almost a third of the respondents expressed interest in Bitcoin as an investment asset in Russia, while in Thailand less than $10 \%$. A certain conservatism of Thai business in the field of investment, the priority of traditional assets against the background of the growing market for digital instruments [19], persists to this day.

4. The overwhelming majority of those polled both in Russia and in Thailand believe that Bitcoin is able to become the leading means of payment in the near future, however, it will not be able to displace official currencies, as well as the currently existing world currencies, while maintaining the relatively high impact of the policy of national banks and governments on the functioning of financial markets.

5. Most of the interviewed Thai experts believe that the state should not actively intervene in the Bitcoin and blockchain infrastructure development and integration into the economy, retaining the role of regulator of the process of Bitcoin converting into real assets (for example, currency) and no more. Russian experts to a greater extent share the need to form a digital investment system autonomous from the traditional asset market, in the interaction of which only market instruments should be present (for example, an exchange system for determining the Bitcoin rate in rubles). At the same time, both Thai and Russian experts are confident that the state should form effective and innovative measures to protect the interests of investors in cryptocurrencies, systems for tracking fraudulent transactions, data theft, and so on.

6. It is worth noting separately the greater optimism regarding the prospects for the introduction of Bitcoin on the part of Thai women - experts (the figure is $16 \%$ higher than that of men) and Russian men (the figure is 32\% higher for women). The most optimistic about Bitcoin are both Thai and Russian experts with up to 10 years of professional experience, mainly representing the consulting industry. Business owners, both in Russia and in Thailand, are the greatest pessimists regarding the prospects of Bitcoin implementation in official payments and turnover.

7. The industry affiliation of Russian and Thai experts also has a significant impact on the level of their optimism regarding cryptocurrency development. So, in Russia, the most innovative, optimistic about the prospects of Bitcoin are high-tech industries, as well as areas with traditionally minimal fixed assets - services, logistics, trade. In Thailand, on the contrary, financiers are seeking to bring the introduction of Bitcoin closer (obviously, in search of opportunities to reduce government regulation of financial transactions and international payments), as well as businesses actively integrated into world economic 
relations - tourism, hotels, transport. The construction, industrial, and agricultural sectors remain conservative and pessimistic about the prospects for Bitcoin in both Thailand and Russia.

\section{Limitations and discussion}

The main limitations associated with this study are that experts from two countries - Russia and Thailand were analyzed in it, none of which can currently be considered a leader in the development of the blockchain, cryptocurrency circulation, reform in the direction of the Digital Economy. These countries have the potential for their own innovative modernization [20], of course, however, at present, the opinion of experts cannot be as representative as possible and accurately reflect the potential for the introduction of Bitcoin in Russia or Thailand, but can be used as a benchmark to determine the foundations for further transformations of the economy and system state regulation of both countries.

Also, representatives of government agencies, including those responsible for financial regulation and foreign exchange control [21], did not take part in the study. Undoubtedly, taking into account the opinion of the state, which has a certain competence and infrastructural capabilities of cryptocurrency circulation, would have a significant impact on the results of assessing the prospects for Bitcoin wide introducing (this task is in a parallel scientific study of the team of authors).

As a result of the survey, expert information was obtained on the priority directions of reforming the existing models of the financial market and the structure of currency and financial regulation, which will be used in further research in order to form a set of recommendations for modernizing the socio-economic systems of Russia and Thailand.

\section{Conclusions and recommendations}

Blockchain made itself known to the world at the very moment when such a secure and reliably protected from outside interference technology of digital data storage is capable of producing a colossal effect. The application of this technology can trigger chain reactions in business models and processes, supply chains and company-customer relationships across all sectors of the global economy.

Blockchain technology has the potential to disrupt many industries that rely on intermediaries or require strong centralized governance. It will provide an opportunity to replace the existing model with an algorithm that provides trust between peers.

The direction of blockchain technology development in the financial sector is considered one of the most promising, which is associated with the growing business needs of this sector of the economy for increased security of online payments, which can be achieved precisely using support of decentralized technology; implementation and distribution of cryptocurrencies.

At this stage, there are no standard models in the regulation of the cryptocurrency market, the development of positions on working with it is slow and the methodology has not yet been built. This significantly slows down the development of technology. The main task of the state, supporting the development of distributed technology, is to develop a clear concept of how the technology can be used to improve the business processes of both government agencies and businesses.

A survey of experts from Russia and Thailand showed that to accelerate the development of cryptocurrency turnover (for example, Bitcoin), it is necessary, among other things, to implement blockchain technology into the business itself. Meanwhile, according to the interviewed experts, the business majority is simply not ready for 
openness, decrease in autonomy, increase in dependence on external factors, which are the conditions for the implementation of both the blockchain in general and cryptocurrencies in particular.

According to the results obtained, the business communities of Thailand and Russia are ready to use the advantages provided by cryptocurrencies (calculations, first of all, attempts to reduce the severity of government regulation), but only in the short term. At the same time, the business community does not hide the desire to reduce its own dependence on measures of state financial regulation with the help of cryptocurrencies, but requires an increase in the state's responsibility for ensuring the security of cyber space for business.

In general, this testifies to the immaturity of idea of Russian and Thai business about cryptocurrency, the presence of numerous institutional and infrastructural problems that stand in the way of cryptocurrency circulation in these countries, despite a certain positive in assessing the prospects of the latter.

\section{References}

1. D. Floyd, Bank Of America, Jpmorgan Call Cryptocurrencies A Threat. Investopedia (2019) https://www.investopedia.com/news/bank-america-calls-cryptocurrencies-riskits-business/

2. J. Naughton, Why Bitcoin Scares Banks And Governments. Guardian (2020) https://www.theguardian.com/technology/2013/apr/07/bitcoin-scares-banksgovernments

3. F. García-Monleón et al., Technological Forecasting and Social Change 162 (2021)

4. N. Trubnikova, The EUrASEANs: J. on Global Socio-Economic Dynamics 1(1), 27-36 (2016)

5. L. Fortney, Bitcoin Mining, Explained. Investopedia https://www.investopedia.com/terms/b/bitcoin-mining.asp

6. Y. Liu, A. Tsyvinski, Risks And Returns Of Cryptocurrency (2018) http://www.nber.org/papers/w24877

7. M. Kubat, Procedia Economics and Finance 30, 409-416 (2015)

8. D Ushakov et al., J. of Advanced Research in Law and Economics 10(8), 2566-2573 (2019)

9. C. Alexakis et al., Espacios 40(10) (2019)

10. C. Albrecht et al., Ledger 5 (2020)

11. K Little, Stock Share Price Vs. Market Cap. The Balance (2020) https://www.thebalance.com/why-per-share-price-is-not-important-3140791

12. V. Naimy et al., PLoS ONE 16(1) (2021)

13. S. Kim, Ledger 6 (2021)

14. K. Cortez et al., Mathematics 9(1), 56 (2021)

15. Y. Zhao, Cryptocurrency Brings New Battles Into The Currency Market (2015) https://www.net.in.tum.de/fileadmin/TUM/NET/NET-2015-03-1/NET-2015-031_13.pdf

16. I. Fomina et al., Lecture Notes in Networks and Systems 111 (2020)

17. E. Dudukalov et al., Contemporary Economics 10(4), 299-310 (2016)

18. F. Glaser et al., Bitcoin - Asset or Currency? Revealing Users' Hidden Intentions (2014) https://papers.ssrn.com/sol3/papers.cfm?abstract_id=2425247) 
19. S. Saengchai, K. Jermsittiparsert, International J. of Supply Chain Management 8(5), 733-744 (2019)

20. O. Takhumova et al., J. of Applied Economic Sciences 13(7), 1939-1944 (2018)

21. E. Dudukalov et al., Entrepreneurship and Sustainability Issues 8(2), 972-983 (2020) 